\title{
Does Moving Disrupt Campaign Activity?
}

\author{
Jake Bowers \\ Department of Political Science, University of Michigan, Ann Arbor
}

\begin{abstract}
Findings from cross-sectional studies cannot tell us whether moving leads to changes in civic activity, because such studies do not observe the same individual's participation before and after moves. This paper treats both moving and participation as dynamic processes, analyzing data that cover 18 years within lives of two generations of Americans. The results suggest that our general understanding about who participates cannot account for the patterns evident in even the simplest of descriptions of this phenomenon. Moving is shown to disrupt moments of campaign activity. However, the specific patterns of this disruption across generations and types of acts lead to more questions about the mechanism by which moving interferes with the political activity of ordinary Americans.
\end{abstract}

KEY WORDS: political participation, residential mobility, dynamics, longitudinal study

America has often been singled out as a "nation of movers" (Lieberson \& Waters, 1987, p. 802), and it is a common perception among sociologists and social critics that "rootlessness" is both a pervasive feature of American life and a powerful cause of a variety of social and civic ills despite its possible economic benefits. ${ }^{1}$ Political scientists have added yet more reason for concern, showing that people who have recently moved to a new place are less likely to vote than people who have lived in that place for a long time. ${ }^{2}$ Robert Putnam (2000) tied the aggregate and individual-level findings together: "Just as frequent movers

\footnotetext{
${ }^{1}$ Fischer (2002) presented a good summary of what social theorists fear from a rootless nation. Thanks to Paul Martin for suggesting the "nation of joiners / nation of movers" link.

2 This hypothesis has been confirmed by Wolfinger and Rosenstone (1980) with data from the Current Population Survey (CPS) in the 1970s, by Squire et al. (1987) with both CPS and NES data from 1980, by Rosenstone and Hansen (1993, pp. 157-159) with data from the 1956-1988 NES Cumulative File, and by Highton (2000) with NES data for presidential election years from 1976 to 1996. For other analyses showing that residential mobility depresses vote turnout, see Verba and Nie (1972, p. 139) and Lane (1959, p. 267).
} 
have weaker community ties, so too communities with higher rates of residential turnover are less well integrated ... So mobility undermines civic engagement ..." (p. 205). ${ }^{3}$

In the aggregate, residential mobility has not appreciably changed in the last 50 years. And, in fact, any change in mobility that has occurred has been a decrease: Around 1950, for example, as many as 1 in 5 Americans were moving, but that proportion has dropped to about 1 in 6 today (Fischer, 2002). Hence, the decline in aggregate civic engagement over time cannot be blamed on residential mobility's effects. Putnam recognized this fact: "Could rising mobility thus be the central villain of our mystery? The answer is unequivocal: No" (Putnam, 2000, p. 205).

Despite the evidence linking voting to residential mobility, and the theory suggesting that tight social ties (presumably resulting in part from residential stability) should spur other forms of civic engagement, the linkages between mobility and other forms of participation, such as donating money or volunteering for campaign work, are weaker. For example, Rosenstone and Hansen (1993) found that, relative to newcomers, longtime residents were only about 3 percentage points more likely to work in a campaign and were not more likely to donate money. Thus, although we have a strong sense for how moving affects who votes, we understand less well how moving may influence nonvoting electoral participation. This paper analyzes voting alongside other types of campaign participation in order to remedy this hole in the literature.

More important, the fact that we understand "who participates" does not mean that we know "when people are apt to participate." In fact, it is a leap to move from "who participates" to an understanding about how changes in mobility influence changes in participation. Unfortunately, findings from cross-sectional studies cannot tell us whether moving (or staying) leads to changes in civic activity, because such studies do not observe the same individual's participation before and after moves. However, this is the causal story that all studies of mobility and participation desire to tell. Of course, astute analysis and interpretation of crosssectional data have yielded causal propositions that seem as if they should be confirmed when tested directly as interventions in a time series of events. For example, there is no dispute that when registration laws are changed, the total proportion of people turning out to vote changes as well (although this change may be small). The analyses presented here ask the "when" question directly, using data that cover 18 years within the lives of two generations of Americans. The results suggest that our general understanding about who participates cannot account for the patterns evident in even the simplest of descriptions of this dynamic phenomenon. However, while moving is shown to disrupt moments of campaign activity (including voting), the specific patterns of this disruption across

\footnotetext{
3 "Integrated" in this context refers to the strength of social ties between individuals within a place. This is not a reference to a place that is racially heterogeneous.
} 
types of activities and generations raise more questions about the mechanism by which moving interferes with the political activity of ordinary Americans.

\section{How Might Moving Disrupt Campaign Activity?}

Nearly all current explanations for the political participation of individuals say that individuals act based on some "soft" conception of their self-interest (see, e.g., Green \& Cowden, 1992). Those individuals who possess civic skills (i.e., the communicative and organizational abilities used in common forms of political participation) are more likely to engage in such activities than those who do not (Verba, Schlozman, \& Brady, 1995), because such skills (and other resources like money) decrease the costs in the cost-benefit calculus presumably surrounding participation decisions. In addition, several authors have pointed out that influence in a society is crucially constrained by status within institutionschanneling the resources that individuals may bring to bear on the pursuit of their interests (see, e.g., Nie, Junn, \& Stehlik-Barry, 1996). Above and beyond the influence of skills or status, people who have been asked to participate are also much more likely to do so than those who have not been asked (Rosenstone \& Hansen, 1993; Verba et al., 1995); this mobilization ought to increase social benefits from participation and/or increase the social costs of not participating. ${ }^{4}$

The effect of residential mobility on nonvoting participation occurs, according to scholarly consensus, because of disruptions to "social connectedness." 5 Social connectedness can be thought of as linked to political participation by two main mechanisms. First, new arrivals are supposedly less likely to know their neighbors (or others in their new towns), and this lack of acquaintance with others also prevents mobilizers from knowing the newcomers, excluding them from mobilization efforts. That is, when people are new to a town, they know fewer people and fewer people know them. For example, Rosenstone and Hansen (1993, p. 167) showed that people who have lived in the same place for most of their lives are more likely to be contacted by members of a political party than those who are more recent arrivals. Second, before a person engages in political activity, she must know something about the issues "on the table", and she must have some sense of what the stakes are for herself and those she cares about. Huckfeldt (1979) pointed out that when it comes to political participation,

\footnotetext{
${ }^{4}$ One might also refer to concepts such as the "life cycle," "period," or "cohort" to explain the development of political participation over the lives of individuals. Space constraints prevent me from adequately addressing these explanations here. See Bowers (2003) for an extended discussion of such effects in the context of political participation.

${ }^{5}$ This is one area where the story about voting diverges from stories about other forms of participation. Highton (2000), for example, showed that the effect of merely switching houses within the same community is as powerful as changing communities in predicting turnout. This finding implies that the need to register to vote is a much more important factor preventing turnout than any social costs or benefits affiliated with the length of time a person has lived in a place.
} 
people cannot be thought of as acting in isolation, but that "[p]eople also respond to political events, cues, and opportunities which are specific to a given environment" (p. 579). That is, in addition to knowing and being known by other people, one must have some information about what is going on, and what is at stake, in any given opportunity for participation. Thus, moving can be thought of as imposing costs on a person (1) by disrupting the conduits for mobilization (knowing people), (2) by requiring individuals to gather new information and understandings about their new political environments, (3) by imposing costs of time and money that are higher than normal due to the process of getting from one residence to another, and, for voting, on top of all of this, (4) by imposing a requirement to re-register. The requirement for new information gathering relates the social connectedness arguments to the civic skills findings, as does the appreciation that action is difficult without information. The importance of knowing others (and being known by them) relates the social connectedness arguments to both the mobilization and the status findings. Overall, at the base of explanations of political participation as an outcome of social networks is the appreciation that political activities tend to occur in groups, that information about these activities is communicated by word of mouth between people who know one another, and that a person's understanding of what activities or policies matter to them depends at least in part on social interactions.

In the end, this discussion yields a clear set of expectations about what a dynamic test of the relationship between residential mobility and participation should reveal: Moving ought to decrease the probability that a person will get involved in any kind of campaign activity in any given moment in time. And voting should be most strongly affected by moving, because it should be depressed both by loss of social networks and also by the costs imposed by the requirement to register to vote after each move.

\section{Data: The Political Socialization Panel Study}

The analyses in this paper rely on a longitudinal study of parents and children that was carried out at the Survey Research Center and Center for Political Studies at the University of Michigan from 1965 to 1997 (Jennings \& Stoker, 1997). This panel study began in 1965 with in-person interviews with a national random sample of 1,669 high school seniors and their parents. ${ }^{6}$ The high school seniors (Generation 2, denoted "G2" here for convenience) and one of their parents (Generation 1, denoted "G1") were reinterviewed in 1973 and 1982. In 1997 the members of G2 were interviewed, but their parents were not. The data

\footnotetext{
${ }^{6}$ The respondents were selected based on an equal probability sample of high schools, and students were randomly selected within high schools.
} 
set I use here contains data for three interviews, over 18 years, with 935 members of the high school class of 1965 and with 898 of their parents. ${ }^{7}$

During the interviews (in 1973 and 1982 for G2, and in 1965, 1973, and 1982 for G1), respondents were asked to recall, explain, and date past campaign participation. In addition to questions about vote turnout, the following questions were asked:

Campaign rallies: "Have you gone to any political meetings, rallies, dinners, or other things like that since (1965/1973)? When was that?"

Campaign work: "Have you done any other work for a party, candidate, or issue since (1965/1973)?"

Campaign button: "Have you worn a campaign button or put a campaign sticker on your car since (1965/1973)? When was that?"

Campaign donation: "Have you given money or bought any tickets to help a particular party, candidate, or group pay campaign expenses since (1965/1973)? When was that?"

This data set allows me to reconstruct annual participation histories over long periods for two generations of Americans. ${ }^{8}$ In fact, this is the only source for histories of participation that last beyond 6 years, and it is also the only source that allows researchers to recover annual information about political participation. In addition to the participation questions, the respondents were asked to report on their past residential mobility, listing the cities/towns and states in which they lived and the number of years they lived in those places. This information allowed me to construct series recording the years in which respondents moved.

Figure 1 shows a random sample of 20 individuals, from both generations, who reported engaging in any of the four acts of political participation listed above. Each of the 20 panels displays the participation series and residential mobility series for a single individual. A vertical line appears above the dotted line each time a person reported participating in one or more campaign activities. Similarly, each move is indicated by a vertical line hanging below the dotted line. Person 137, for example, reported moving in each of the years between 1966 and 1970 as well as in 1974; he also engaged in at least one of the four types of nonvoting political activity in 1970 and 1972.

Many people participated in nonvoting campaign activities more than once over this period-or even up to three times in a single year. For example, a few

\footnotetext{
${ }^{7}$ Comparisons between those individuals who dropped out of the study after the first wave and those individuals who stayed in until 1982 showed that those who stayed were slightly more liberal and slightly more politically involved than those who did not. However, see Jennings and Niemi (1981, appendix A) and Jennings and Markus (1984) for more analyses showing that panel respondents continued to represent their cohort quite well over time.

${ }^{8}$ While nearly everyone in the G2 cohort was born in 1947 or 1948, the mean (and median) age of members of G1 in 1965 was 46 (the middle $50 \%$ of G1 were 42 to 50 years old). Thus, the age of the G2 cohort increases from 18 to 35 over the course of the first three waves of the study, and that of the G1 group increases from roughly 46 to roughly 63 .
} 

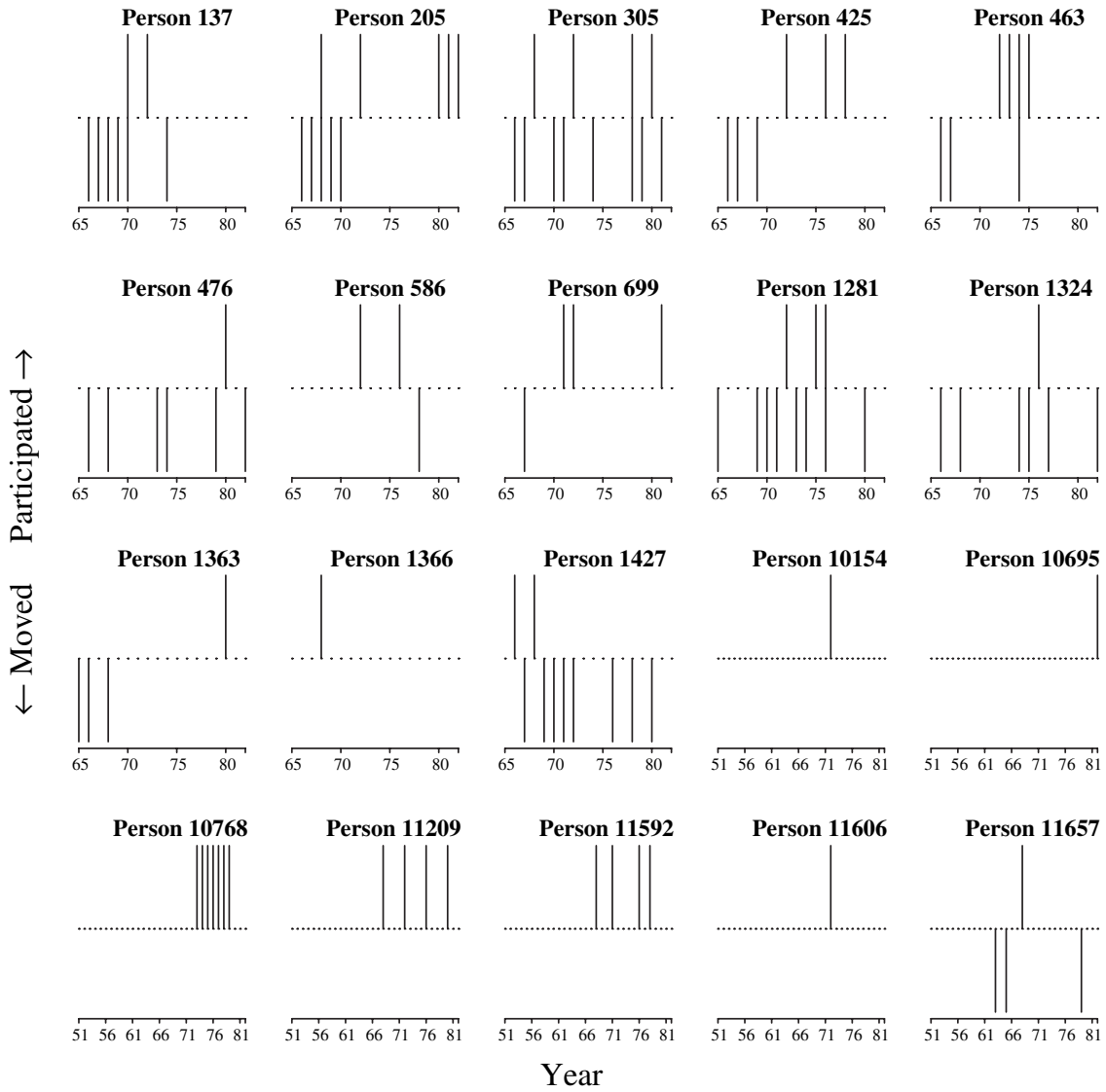

Figure 1. Individual histories of participation and residential mobility.

Note: The $x$ axis runs from 1951 to 1982 for G1 since members of that generation were able to report both participation and residential mobility for the years preceding 1965 in the 1965 interview.

people in G1 attended as many as four campaign events, wore buttons or showed signs four times, volunteered for campaigns four times, or donated money five times over this period. ${ }^{9}$ The members of G2 were more active than those of G1 in all of these activities: A few attended as many as 18 rallies, wore buttons 10 times, volunteered for campaigns nine times, and donated money 10 times during the 18 years of the study. ${ }^{10}$ Voting behavior is not shown in this figure. The

\footnotetext{
${ }^{9}$ One or two members of G1 went to as many as nine rallies, wore buttons 18 times, worked for campaigns nine times, and donated money 24 times over the 18 years spanned by this study.

${ }^{10}$ One or two members of G2 went to as many as 28 campaign meetings or rallies, wore buttons or displayed signs 29 times, worked for campaigns 20 times, and donated money 28 times over the 18 years spanned by this study.
} 
proportion of G1 who reported voting remained constant across the presidential elections in this period; between 80 and $90 \%$ reported voting each time. The proportion of G2 who reported voting in 1968 was around 55\%, in 1972 it rose to around $75 \%$, and by 1976 it had reached parity with the turnout rates of G1.

Just about $25 \%$ of G1 moved at least once over this time period (15\% moving just once, $5 \%$ moving twice, $3.5 \%$ moving three times, $1.8 \%$ moving four or more times, up to a maximum of six times). It is well known that the young move more than the old, and this fact is confirmed in the Political Socialization data: Nearly $89 \%$ of G2 moved at least once between ages 18 and 35 (with $16 \%$ moving just once, $12 \%$ moving twice, $14 \%$ moving thrice, and $47 \%$ moving four or more times, up to a maximum of 10 moves).

Figure 1 on its own does not appear to provide much purchase for understanding the dynamic relationship (if any) between residential mobility and political participation. Some individuals, like Person 425, display patterns in which political participation appears to wait until moving stops. Others, like Person 305, seem to participate in politics whether or not they are moving. We commonly think of civic skills, status, and other politically relevant resources as changing slowly over time or as stable after a certain age. If this is so, then how could such stable characteristics drive the quickly changing process shown here? For example, people do not gain and lose education from one year to the next, so how can education be seen as a cause of political participation? It is beyond the scope of this paper to propose and test the alternative explanations necessary to encompass these patterns. However, moving does appear to be the kind of phenomenon that occurs nearly as quickly as the irregular and sporadic series of participation events. Thus, in addition to findings and theories relating campaign activity to residential mobility, moving also appears to qualify as a plausible direct inhibitor of political participation.

\section{Analyses and Results}

A model of a longitudinal process such as political participation within the lives of people must take into account (1) correlation of observations across time, within person; (2) unmeasured heterogeneity across people; and (3) the fact that the probability distribution presumably generating the 0 s and $1 \mathrm{~s}$ marking moments of participation (and moments of inaction) is not Normal. One type of model that can handle these requirements is known as a generalized linear mixed-effects model, also known as a multilevel or random coefficients model with non-Normal dependent variables. ${ }^{11}$ I describe this model in the Appendix.

Each model included a number of explanatory variables in addition to an indicator of whether the person moved in a given year. We know that age ought to

${ }^{11}$ See Raudenbush and Bryk (2002) and Snijders and Bosker (1999) for more details about these models, and Diggle, Liang, and Zeger (1994) for specific information about longitudinal versions. 
predict both moving and participation, and so it must be in the model in order to avoid confounding the estimates of the effects of moving-people move more when they are young than when they are old. I also expected income and education to predict both moving and participation-income and education ought to make both moving and participation easier. The model also included dummy variables for interview years to account for the tendency of individuals to recall better both participation and moving events during those years than during other, more distant years.

Previous research has operationalized the concept of "residential mobility" using a measure of "amount of time living in a given location" (in essence using residential stability to represent residential mobility). The findings compare relative newcomers to long-time residents. For example, Squire, Wolfinger, and Glass (1987) used the 1980 National Election Study (NES) to show that people who have lived in one place for less than 2 years are no more or less likely to display campaign buttons or signs, work for a party or candidate, attend political meetings, or join political organizations or clubs than people who have lived in one place for more than 2 years. However, the difference in registration (and thereby in vote turnout) is nearly 20 percentage points across those two groups in their analysis. The analysis that I present here examines the disruptive effects of moving more directly, by using information about whether a person moved in a given year to predict that person's participation in that year. Thus, this analysis is a test of "moving" rather than of residential stability and tenure.

The main expectation for results from these models is that when people move, their probability of participation ought to be lower than when they do not move. Because the data are annual, this means that inference will be based on comparisons among years within the lives of people. So this expectation can be restated: years when people move should be years when people participate less (compared to years when people do not move).

Of course, not all types of participation ought to be affected equally by the expected disruption of moving. Scholars have very strong priors that voting should be much less likely to occur immediately after a move to a new location. There are no institutional barriers such as voter registration to prevent participation in any of the campaign activities analyzed here. However, all of them ought to be susceptible to influence by social networks. Showing public support for a candidate or issue via signs and buttons requires some understanding about how other people who see these symbols will react to them; less knowledge about local norms would seem to make public political stands a bit more of a risky business (at least from the point of view of a newcomer considering the creation of a new reputation). Donating one's time to a campaign - by attending events or, more intensively, by volunteering as a campaign worker-tends to occur in a person's local area; thus, local political knowledge (and being known by local political operatives or at least being within a social network easily reached by such operatives) should be a necessary condition for these two activities. Donating money 
Table 1. Estimated Effects of Moving on Participation (percentage points)

\begin{tabular}{lccrrr}
\hline & Rallies/meetings & Campaign work & Money & Buttons & \multicolumn{1}{c}{ Vote } \\
\hline Youth & -1.82 & -7.81 & 2.23 & -8.85 & -4.77 \\
Parents & -6.63 & -8.34 & -26.18 & -33.56 & -12.77 \\
\hline
\end{tabular}

Note. These effects are calculated with reference to a person who has a $50 \%$ probability of engaging in a given action. See Appendix A for the full results, including a description of how these effects were calculated.

presumably would suffer the least from the effects of moving (because it can be most easily done alone) and would appear to require less local knowledge of issues or norms even than wearing campaign buttons (because it is also more private).

Table 1 presents the estimated effects of moving. These are the maximum possible effects of moving given the coefficient estimates (see the Appendix for a detailed explanation). ${ }^{12}$

The discussion of these results should begin with the effect of moving on the vote, because that is the area in which all of the past cross-sectional analysis agrees. In this analysis, presidential election years in which people move ought to be ones in which they are much less likely to vote. The analysis in Table 1 shows that the effect of moving for both G1 and G2 is to depress turnout-by about 4.8 percentage points $(p \approx .07)$ for the younger generation and by about 12.8 percentage points $(p=.12)$ for the older generation. ${ }^{13}$ Neither of these effects is as strong as expected. For example, Squire et al. (1987) found cross-sectional effects of residential mobility on probability of vote turnout in the range of 20 percentage points. However, the effects reported here are not nearly as large, nor do they cast much doubt on the null hypothesis of no effects.

Among the younger generation, campaign work and wearing buttons are depressed during years in which these people move [by roughly 8 points $(p \approx$ $.05)$ and 9 points $(p=.004)$, respectively]. And attendance at campaign rallies and meetings is also depressed, but only slightly [by about 2 percentage points, which is indistinguishable from zero $(p \approx .30)]$. These findings suggest that moving is acting via at least two paths among G2-by breaking the social networks that would mobilize individuals to join campaigns, and by changing the issue environment that would make certain buttons, stickers, or signs relevant (and socially acceptable) to display. In contrast, and as expected, donating money

${ }^{12}$ Because the acts analyzed here are most commonly done during campaigns, I present only the effects for election years in Table 1. The Appendix contains the full results for models for all years as well as for election years only. The effects for election years tended to be the same (for G2) or somewhat stronger (for G1) than the effects using all possible years.

${ }^{13}$ The $p$ values in the Appendix are for two-sided tests of the null hypothesis of no effect. I report one-sided $p$ values in the text, given the strength of previous research suggesting that moving ought to disrupt and depress participation. 
seems largely untouched by moving among this generation: An increase of 2.23 percentage points is the maximum possible effect for campaign donations among $\mathrm{G} 2(p=.16)$.

Among the older generation, moving appears to depress participation even more than it does among the members of G2. However, the relative paucity of participation (and of moving) among G1 means that these effects are difficult to distinguish from noise. The few effects that really stand out are those for wearing buttons and displaying signs [a decrease of 34 percentage points $(p=.002)]$ and for donating money [again, a very large decrease of 26 percentage points that is quite distant from the null hypothesis of no effects $(p \approx .02)]$. Although one would imagine that campaign work and attendance at campaign meetings and rallies ought to be strongly disrupted by a move, in the case of G1 this did not occur in a way that was distinguishable from zero (although the sizes of the effects of roughly 8 and 7 percentage points are larger than the sizes for the youth).

In these analyses, a year during which a person moves tends to be a year in that person's life during which he or she participates a bit less in electoral politics. But although conventional wisdom and past findings would suggest that voting would bear the brunt of this disruption, this analysis does not strongly confirm that expectation. Probability of voting is predicted to decrease during moving years, but not as strongly as the decreases predicted for other activities. Moreover, the information available to distinguish these effects for voting from zero is not extraordinarily strong.

\section{Discussion}

Although the results presented here largely support the expectation that moving disrupts political participation, they do not do so across all acts and both generations with equal strength. What might the patterns of effects tell us about the mechanism by which moving depresses campaign activity?

If social connectedness had no effects on political participation, and moving only mattered because of registration requirements, then Table 1 would have shown no effects on any of the nonvoting types of political participation, and strong, negative effects on voting. This clearly did not happen. One might interpret this pattern as supporting the idea that social networks matter for all kinds of political participation-including voting. However, Highton (2000) showed that people who move within cities and people who move across states are equally less likely to vote than people who haven't moved at all. This is strong evidence showing that the registration barrier is the most important mechanism linking moving to turnout, and that social networks matter much less for this activity. Since I do not assess registration laws here, a conservative interpretation of this pattern of results would be that voting is truly a different kind of act from the others, and that - although the results don't cast doubt on the power of registration laws to influence voting - the power of residential mobility to depress the 
nonvoting campaign activity of individuals must be drawn from some other mechanism (because one does not need to register before doing any of the other four activities). The most immediately plausible explanations for this negative effect of moving on nonvoting participation have something to do with social networks or the costs of time and money associated with moving.

I previously suggested that social networks might influence political participation via two main mechanisms - knowledge of people and knowledge of issues. Knowing people provides conduits for mobilization, and it is well known that those who are asked to participate are more likely to do so than those who are not asked (for evidence about this, see, e.g., Rosenstone \& Hansen, 1993; Verba et al., 1995). Knowing issues is less well studied, but it is a plausible other mechanism by which social connectedness may operate. It makes sense that an individual ought to know and care about whatever issue, campaign, or candidate is the focus of her participation efforts. Of course, mobilization attempts often involve more than social pressure to get involved. Mobilizers can provide information about issues and help people articulate and understand their interests in the context of a particular political conflict. However, one can imagine that understanding what is at stake in a given issue but not knowing many other people may lead to kinds of political responses different from those that may arise from knowing many people without having much information about what is at stake during a given election.

Huckfeldt (1979) proposed a distinction between "socially based" and "individually based" actions, which can help clarify the two ways that social networks may operate to affect political participation. The idea here is that some activities are more easily (or likely) done by individuals by themselves (such as writing a check to a campaign or wearing a button), whereas other activities are more easily (or likely) done in groups (such as going to a campaign rally or working for a campaign). If socially based activities are most sensitive to moving, then one might speculate that moving is really working by disrupting the conduits for mobilization-knowing other people and being known by them. If individually based activities are most sensitive to moving, then one might speculate that moving functions by affecting how much individuals know about what is going on in politics and how the events and opportunities for political participation matter for them personally. Thus, although the purpose of this paper has not been to understand deeply what it is about moving that matters for political participation, the patterns of results presented can help inform speculation about the mechanisms underlying these effects.

Table 1 shows different patterns of results for the two generations. For the members of $\mathrm{G} 2$, moving has the largest effects on their propensity to wear buttons or display signs and stickers (presumably an individually based act) and to work on campaigns (presumably a socially based act). The effects on attendance at campaign meetings and rallies and on donating money for this generation are indistinguishable from zero. Among the members of G1, the strongest effects are for 
acts that are easy to do alone, such as donating money or showing campaign buttons. The effects of moving on acts that are easiest done in groups (attending campaign meetings and rallies and working for campaigns) are much smaller in this older generation, and although they represent substantively meaningful changes (of 6.6 percentage points and 8.3 percentage points), the models cannot distinguish them from zero very reliably (one-sided $p \approx .30$ for both acts).

These are two different patterns of results, one for each generation. Among the younger generation, moving disrupts one socially based and one individually based. Among the older generation, the socially based acts bear the brunt of the mobility disruption. And, in general, the impact of mobility on the older generation is stronger in effect size than the effects on the younger generation. In neither case are the most time-intensive acts (in this case, the socially based acts) most strongly affected; this finding suggests that the time constraints of moving do not matter as strongly as other factors. Donating money is not affected among the younger generation, which suggests that the monetary costs of moving matter less for this group. The large effect of mobility on donations among G1, however, is consistent with a causal story linking moving to less money to fewer political donations.

So how can we make sense of the suggestion that the older generation is particularly sensitive to disruptions in the issue environment and somewhat less sensitive to disruptions in the web of who knows whom, but that the younger generation is equally sensitive (and insensitive) to both types of damage to their social networks? ${ }^{14}$ Certainly, for moving to have an effect, the individuals in question must be doing something to be affected. We know that the members of G1 vote much more habitually, and with higher probability, than the members of G2 over much of the 1965 to 1982 period (Bowers, 2003; Plutzer, 2002). And we know that the individuals in G1 tend to have higher incomes that those in G2 merely by virtue of being older. ${ }^{15}$ To the previous discussion, therefore, we need to add an appreciation of what are known as "floor effects."

\section{Conclusion}

Decades of research have shown that new arrivals to a place are less likely to vote than old-timers. This information has created a firm understanding of who votes, and a somewhat less strong (but still pervasive) comprehension of what kinds of people engage in other kinds of campaign activities. Whether information about who participates helps us understand when people participate, however,

\footnotetext{
${ }^{14}$ Another problem with interpreting the patterns of effect here is that the acts that I am calling "individually based" are also those that take less time. Thus, the social vs. individual distinction is conflated among these acts with a more time vs. less time distinction.

15 Plutzer (2002) showed that we can understand the voting behavior of these two generations as habits that develop and solidify over the life cycle. I thank Eric Plutzer for suggesting inertia and habit as possible explanations of the pattern of results across generations presented here.
} 
has been an open question. Rough inspection of participation as it changes over the lives of individuals suggests that the causal agents spurring the sporadic episodes of activity must also change quickly, and thus the common explanations based on slowly changing attributes of individuals (such as civic skills, or education more broadly) will not suffice. Residential mobility, however, does have the potential to explain these patterns: People move multiple times in their lives, and seen at a resolution of 1 year, the series of moving events looks similar to the series of participation events. Thus, among the currently powerful explanations of political participation, moving clearly has the potential to help us understand both who participates and when they do so.

The results presented here support the idea that moving disrupts participation, but the particular patterns of disruption are not those that the literature would have led us to expect. First, voting should have taken the largest hit from moving among all of the activities studied, given the requirement to register, and this did not happen. Although moving was predicted to decrease the probability of voting, the decrease was not as large as that for at least two of the other activities, nor did it cast as much doubt on the null hypothesis of no effects as would have been expected.

Second, moving was predicted to impede most strongly those activities that rely heavily on action in groups and that are locally organized (e.g., volunteering for campaigns, attending campaign meetings and rallies, and wearing buttons or otherwise displaying support for a campaign or candidate). People can donate money by themselves; and so, if the theory for the action of moving is about social connections, moving should have much less impact on this act than on the others. This did not turn out to be the case, especially for the older generation; years in which they moved were predicted by the analysis to be years in which the probability of giving money to a campaign was quite low. In addition, moving had no discernible effect on attendance at campaign rallies and meetings for either generation. However, displaying public political support via buttons or stickers was strongly depressed by moving among both generations. In the end, despite the consistent pattern of negative effects, the way that particular acts responded to moving differed, and the arrangement of effects across acts differed across the two generations. These results show that we can add moving to our list of causes for when people participate (and it is comforting that at least one of the predictors of who participates can help predict the dynamic process as well). Nonetheless, the results raise many more questions than they answer about what it is that moving does to hinder political participation.

These questions, however, are beyond the scope of this short paper. They require new analysis, and for some of them, new data collection. Pursuit of some of these avenues has suggested that Americans tend to be very resilient when it comes to moving, and that data gathered at the temporal resolution of a single year do not show consistently strong disruptions in the trajectories of both campaign and non-electoral political participation across the lives of ordinary citizens 
(Bowers, 2003). However, the attempt to understand political participation as a dynamic process - adding an understanding of when people participate to the current knowledge about who participates-is only just beginning.

\section{APPENDIX}

\section{The Models}

The probability model used here assumes that political participation can be seen as draws from a Bernoulli probability distribution, and so the point of the model is not to predict $y_{i t}$ itself but $\operatorname{Pr}\left(y_{i t}=1\right)$. Because the explanatory variables in the model are combined in a linear fashion, this sum (called $\eta_{i t}$ in the parlance of generalized linear models) must be transformed so that it produces only values between 0 and 1 (so that the predicted values can be interpreted as probabilities). I used a logit link function for this purpose. Thus, the structural model really refers to $\eta_{i t}$, which in turn is transformed via the logit link into the probability scale to complete the model. The form of model I use here can be written as

$$
\eta_{i t}=\left(\gamma_{0}+u_{0 i}\right)+\gamma_{1} z_{i}+\left(\gamma_{2}+u_{1 i}\right) \operatorname{Moved}_{i t}+\sum_{k=3}^{K} \gamma_{k} x_{k i t}+e_{i t}
$$

In this model, two of the $\beta$ s commonly seen in linear models are replaced by combinations of $\gamma$ and $u$. These combinations represent the fact that the intercept and slope coefficients (on Moved) are allowed to vary across people. The random intercept $\left[\left(\gamma_{0}+u_{0 i}\right)+\gamma_{1} z_{i}\right]$ specifies that the mean level of participation across people might vary as a function of a characteristic of an individual that is constant over time, $z$ (such as gender), plus some random error $\left(u_{0 i}\right)$ that allows the intercept of the level-1 equation to vary across individuals-capturing aspects of people that may lead them to be more or less participatory that have not been measured in the model, and thus accounting for the possible heteroskedasticity induced by the clustering of years within person. The random slope $\left[\left(\gamma_{2}+\right.\right.$ $\left.u_{1 i}\right)$ Moved $_{i t}$ ] specifies that the extent to which moving influences participation may also vary across individuals; this expresses the idea that there may be idiosyncratic aspects of individuals that cause them to react differently to moving that are not measured. In addition, allowing both the intercept and slope in the level1 model to vary allows one to estimate the extent to which those people who tend to have high values of participation are also those who tend to suffer more (or less) from the disruption of a move. The rest of the coefficients in the model do not vary over individuals (or, if they do vary, that variance does not matter for the estimates of the effect of Moved). The final term, $e_{i t}$, represents the error associated with intraindividual variation in participation not explained by the model. Each of the error terms $u_{0 i}, u_{1 i}$, and $e_{i t}$ are assumed to be draws from a Normal 
probability distribution with mean 0 . The $u$ are allowed to be correlated with one another, but they are not allowed to be correlated with $e_{i t}{ }^{16}$

In addition, since the measurements within individual are probably correlated from year to year, I imposed a continuous AR1 form on the covariances between years, within individual, such that $\operatorname{cov}\left(e_{i j}, e_{i k}\right)=\phi^{l}, j \neq k$, and $l=0,1, \ldots$, where $l$ represents "lag," and so the correlation between adjacent observations is considered to be constant across individuals but dies out quickly as observations get farther apart. Not all models required this, however, and this term was not included for those dependent variables that did not show appreciable temporal dependence in the residuals.

\section{Variables in the Models}

Moved $(0=$ did not move in year $t, 1=$ moved in year $t)$; Age is standardized (mean $=0, s d=1$ ) so that the constant represents the mean participation of someone of average age over the period (this enhances the numerical stability of the maximization algorithm); Education $(0=$ high school only to $1=$ beyond a bachelor's degree, linearly interpolated between interview years); Income (first normed to 1997 dollars and then coded to run from $\min =0$ to $\max =1$, linearly interpolated between interview years); Female (0 if male, 1 if female). Dummy variables for 1965, 1973, and 1982 adjust for the fact that events in years close to those interview years are more likely to be recalled than events in more distant years.

\section{Calculating Effects}

For an explanatory variable that takes on only values of 0 or 1 (such as Moved), we know that, holding all else constant,

$$
\operatorname{Pr}\left(\widehat{y_{i t}}=1\right)=\left\{\begin{array}{c}
\frac{e^{0 \cdot \hat{\beta}}}{1+e^{0 \cdot \hat{\beta}}}=\frac{1}{2}, \text { when } x=0 \\
\frac{e^{1 \cdot \hat{\beta}}}{1+e^{1 \cdot \hat{\beta}}}=\frac{e^{\hat{\beta}}}{1+e^{\hat{\beta}}}, \text { when } x=1
\end{array}\right.
$$

The place on the logit function where a one-unit change in $x$ is assumed to produce the most change in $\operatorname{Pr}(y)$ is at $\operatorname{Pr}(y)=.5$. Thus, calculating the effects with reference to a person who has a $50 \%$ probability of voting produces the maximum effect for a variable given the estimated coefficient. For example, in

${ }^{16}$ The particular estimation strategy I use here involved maximizing the restricted penalized quasilikelihood function and was implemented in Splus via the glme command, provided to me as beta software by José C. Pinheiro. For technical details about the maximum likelihood estimation of generalized linear mixed-effects models like this one, see Breslow and Clayton (1993), Raudenbush and Bryk (2002, chapter 10), McCulloch and Searle (2001, chapter 8), and Snijders and Bosker (1999, chapter 14). 
Table 1, I show that the effect of moving on attendance at campaign rallies and meetings was -1.82 percentage points (using the analysis that contained all years between 1965 and 1982). This was calculated from the estimated coefficient of -0.073 , shown in Table 2 via $\exp (-0.073) /(1+\exp (-0.073))=0.4818-0.50=$ -0.0182 .

The following tables display the results of the estimation of the model described above for each of the types of campaign activity, for all years between 1965 and 1982 (in Tables 2 and 4), and for election years only (the evennumbered years from 1966 to 1982, shown in Tables 3 and 5). The results for

Table 2. Youth Generation, All Years (1965-1982)

\begin{tabular}{|c|c|c|c|c|c|c|c|c|}
\hline & \multicolumn{2}{|c|}{ Rallies/meetings } & \multicolumn{2}{|c|}{ Campaign work } & \multicolumn{2}{|c|}{ Money } & \multicolumn{2}{|c|}{ Buttons } \\
\hline & $\hat{\gamma}$ & $p$ & $\hat{\gamma}$ & $p$ & $\hat{\gamma}$ & $p$ & $\hat{\gamma}$ & $p$ \\
\hline Constant & -5.245 & .000 & -6.619 & .000 & -6.837 & .000 & -5.286 & .000 \\
\hline Moved & -0.096 & .435 & -0.410 & .010 & -0.043 & .739 & -0.418 & .000 \\
\hline Age & 0.262 & .000 & 0.032 & .544 & 0.444 & .000 & -0.048 & .291 \\
\hline Education & 0.752 & .000 & 0.712 & .000 & 1.535 & .000 & 0.219 & .168 \\
\hline Income & 1.214 & .000 & 2.086 & .000 & 2.994 & .000 & 1.380 & .000 \\
\hline Female & -0.118 & .419 & 0.020 & .912 & -0.260 & .115 & 0.012 & .928 \\
\hline 1965 & -0.534 & .000 & -0.377 & .000 & -1.016 & .000 & -0.949 & .000 \\
\hline 1973 & -0.322 & .000 & -0.482 & .000 & -0.504 & .000 & -0.302 & .001 \\
\hline 1982 & 0.171 & .000 & 0.246 & .000 & 0.261 & .000 & 0.233 & .000 \\
\hline $\operatorname{sd}\left(u_{0}\right)$ & \multicolumn{2}{|c|}{1.759} & \multicolumn{2}{|c|}{2.074} & \multicolumn{2}{|c|}{1.945} & \multicolumn{2}{|c|}{1.538} \\
\hline $\operatorname{sd}\left(u_{1}\right)$ & \multicolumn{2}{|c|}{1.764} & \multicolumn{2}{|c|}{1.958} & \multicolumn{2}{|c|}{1.602} & \multicolumn{2}{|c|}{1.612} \\
\hline $\operatorname{cor}\left(u_{0}, u_{1}\right)$ & \multicolumn{2}{|c|}{-0.291} & \multicolumn{2}{|c|}{-0.296} & \multicolumn{2}{|c|}{-0.343} & \multicolumn{2}{|c|}{-0.259} \\
\hline$\phi$ & \multicolumn{2}{|c|}{0.090} & \multicolumn{2}{|c|}{0.077} & \multicolumn{2}{|c|}{0.064} & \multicolumn{2}{|c|}{0.026} \\
\hline LogLik & \multicolumn{2}{|c|}{$-52,689.454$} & \multicolumn{2}{|c|}{$-57,537.584$} & \multicolumn{2}{|c|}{$-58,145.542$} & \multicolumn{2}{|c|}{$-51,551.526$} \\
\hline
\end{tabular}

Note. Total number of individuals is 935 ; total number of person-years is 16,660 .

Table 3. Youth Generation, Election Years Only

\begin{tabular}{|c|c|c|c|c|c|c|c|c|c|c|}
\hline & \multicolumn{2}{|c|}{ Rallies/meetings } & \multicolumn{2}{|c|}{ Campaign work } & \multicolumn{2}{|c|}{ Money } & \multicolumn{2}{|c|}{ Buttons } & \multicolumn{2}{|c|}{ Vote } \\
\hline & $\hat{\gamma}$ & $p$ & $\hat{\gamma}$ & $p$ & $\hat{\gamma}$ & $p$ & $\hat{\gamma}$ & $p$ & $\hat{\gamma}$ & $p$ \\
\hline Constant & -4.295 & .000 & -5.646 & .000 & -5.043 & .000 & -3.723 & .000 & 0.848 & .000 \\
\hline Moved & -0.073 & .613 & -0.315 & .093 & 0.089 & .316 & -0.358 & .008 & -0.192 & .130 \\
\hline Age & 0.263 & .000 & -0.051 & .411 & 0.387 & .000 & 0.030 & .558 & 0.679 & .000 \\
\hline Education & 0.886 & .000 & 0.685 & .000 & 1.414 & .000 & 0.277 & .105 & 2.307 & .000 \\
\hline Income & 0.852 & .002 & 1.714 & .000 & 2.908 & .000 & 1.355 & .000 & 1.074 & .004 \\
\hline Female & -0.128 & .426 & -0.005 & .980 & -0.298 & .081 & -0.012 & .926 & -0.154 & .236 \\
\hline 1982 & -0.537 & .000 & -0.032 & .775 & -0.908 & .000 & -1.037 & .000 & & \\
\hline $\operatorname{sd}\left(u_{0}\right)$ & \multicolumn{2}{|c|}{1.932} & \multicolumn{2}{|c|}{2.161} & \multicolumn{2}{|c|}{1.983} & \multicolumn{2}{|c|}{1.605} & \multicolumn{2}{|c|}{1.635} \\
\hline $\operatorname{sd}\left(u_{1}\right)$ & \multicolumn{2}{|c|}{2.077} & \multicolumn{2}{|c|}{2.417} & \multicolumn{2}{|c|}{0.241} & \multicolumn{2}{|c|}{1.930} & \multicolumn{2}{|c|}{1.683} \\
\hline $\operatorname{cor}\left(u_{0}, u_{1}\right)$ & \multicolumn{2}{|c|}{-0.369} & \multicolumn{2}{|c|}{-0.414} & \multicolumn{2}{|c|}{-1.000} & \multicolumn{2}{|c|}{-0.387} & \multicolumn{2}{|c|}{-0.432} \\
\hline$\phi$ & \multicolumn{2}{|c|}{0.036} & \multicolumn{2}{|c|}{0.042} & \multicolumn{2}{|c|}{0.007} & & & \multicolumn{2}{|c|}{0.078} \\
\hline LogLik & \multicolumn{2}{|c|}{$-24,965.916$} & \multicolumn{2}{|c|}{$-27,097.773$} & \multicolumn{2}{|c|}{$-26,342.308$} & \multicolumn{2}{|c|}{$-23,837.502$} & \multicolumn{2}{|c|}{$-9,276.657$} \\
\hline
\end{tabular}

Note. Total number of individuals is 935 ; total number of person-years is 8,405 (3,736 for Voting). 
Table 4. Parent Generation, All Years (1965-1982)

\begin{tabular}{|c|c|c|c|c|c|c|c|c|}
\hline & \multicolumn{2}{|c|}{ Rallies/meetings } & \multicolumn{2}{|c|}{ Campaign work } & \multicolumn{2}{|c|}{ Money } & \multicolumn{2}{|c|}{ Buttons } \\
\hline & $\hat{\gamma}$ & $p$ & $\hat{\gamma}$ & $p$ & $\hat{\gamma}$ & $p$ & $\hat{\gamma}$ & $p$ \\
\hline Constant & -5.590 & .000 & -7.498 & .000 & -5.506 & .000 & -5.970 & .000 \\
\hline Moved & -0.048 & .891 & 0.048 & .912 & -0.638 & .115 & -0.374 & .333 \\
\hline Age & 0.112 & .027 & -0.088 & .102 & 0.328 & .000 & -0.039 & .441 \\
\hline Education & 0.819 & .000 & 1.267 & .000 & 1.697 & .000 & 0.122 & 610 \\
\hline Income & 1.827 & .000 & 2.396 & .000 & 1.565 & .000 & 1.343 & .000 \\
\hline Female & -0.302 & .062 & 0.098 & .656 & -0.605 & .000 & -0.339 & .035 \\
\hline 1965 & -0.408 & .000 & -0.528 & .000 & -0.734 & .000 & -1.098 & .000 \\
\hline 1973 & -0.215 & .002 & -0.275 & .000 & -0.291 & .000 & -0.234 & .019 \\
\hline 1982 & 0.228 & .000 & 0.342 & .000 & 0.274 & .000 & 0.236 & .000 \\
\hline $\operatorname{sd}\left(u_{0}\right)$ & \multicolumn{2}{|c|}{1.714} & \multicolumn{2}{|c|}{2.130} & \multicolumn{2}{|c|}{1.684} & \multicolumn{2}{|c|}{1.744} \\
\hline $\operatorname{sd}\left(u_{1}\right)$ & \multicolumn{2}{|c|}{2.249} & \multicolumn{2}{|c|}{2.381} & \multicolumn{2}{|c|}{2.090} & \multicolumn{2}{|c|}{1.844} \\
\hline $\operatorname{cor}\left(u_{0}, u_{1}\right)$ & \multicolumn{2}{|c|}{-0.378} & \multicolumn{2}{|c|}{-0.595} & \multicolumn{2}{|c|}{-0.350} & \multicolumn{2}{|c|}{-0.445} \\
\hline$\phi$ & \multicolumn{2}{|c|}{0.007} & \multicolumn{2}{|c|}{0.016} & \multicolumn{2}{|c|}{0.007} & \multirow{2}{*}{\multicolumn{2}{|c|}{$-51,999.248$}} \\
\hline LogLik & $-51,8$ & 572 & $-58,0$ & 544 & $-52,1$ & 833 & & \\
\hline
\end{tabular}

Note. Total number of individuals is 895 ; total number of person-years is 15,680 .

Table 5. Parent Generation, Election Years Only (Even years from 66 to 82)

\begin{tabular}{|c|c|c|c|c|c|c|c|c|c|c|}
\hline & \multicolumn{2}{|c|}{ Rallies/meetings } & \multicolumn{2}{|c|}{ Campaign work } & \multicolumn{2}{|c|}{ Money } & \multicolumn{2}{|c|}{ Buttons } & \multicolumn{2}{|c|}{ Vote } \\
\hline & $\hat{\gamma}$ & $p$ & $\hat{\gamma}$ & $p$ & $\hat{\gamma}$ & $p$ & $\hat{\gamma}$ & $p$ & $\hat{\gamma}$ & $p$ \\
\hline Constant & -4.744 & .000 & -6.598 & .000 & -4.402 & .000 & -4.294 & .000 & 2.031 & .000 \\
\hline Moved & -0.267 & .609 & -0.337 & .605 & -1.162 & .049 & -1.626 & .004 & -0.522 & .235 \\
\hline Age & 0.129 & .024 & 0.068 & .263 & 0.336 & .000 & 0.020 & .729 & 0.584 & .000 \\
\hline Education & 0.798 & .001 & 1.105 & .000 & 1.509 & .000 & 0.096 & .695 & 1.359 & .000 \\
\hline Income & 1.846 & .000 & 2.585 & .000 & 2.077 & .000 & 1.443 & .000 & 1.856 & .000 \\
\hline Female & -0.335 & .052 & 0.113 & .623 & -0.588 & .000 & -0.268 & .101 & -0.577 & .001 \\
\hline 1982 & -0.254 & .051 & -0.110 & .408 & -0.475 & .000 & -1.037 & .000 & & \\
\hline $\operatorname{sd}\left(u_{0}\right)$ & \multicolumn{2}{|c|}{1.798} & \multicolumn{2}{|c|}{2.145} & \multicolumn{2}{|c|}{1.708} & \multicolumn{2}{|c|}{1.718} & \multicolumn{2}{|c|}{1.986} \\
\hline $\operatorname{sd}\left(u_{1}\right)$ & \multicolumn{2}{|c|}{2.965} & \multicolumn{2}{|c|}{2.761} & \multicolumn{2}{|c|}{2.182} & \multicolumn{2}{|c|}{1.820} & \multicolumn{2}{|c|}{1.724} \\
\hline $\operatorname{cor}\left(u_{0}, u_{1}\right)$ & \multicolumn{2}{|c|}{-0.565} & \multicolumn{2}{|c|}{-0.484} & \multicolumn{2}{|c|}{-0.434} & \multicolumn{2}{|c|}{0.120} & \multicolumn{2}{|c|}{0.016} \\
\hline LogLik & \multicolumn{2}{|c|}{$-24,014.303$} & \multicolumn{2}{|c|}{$-26,836.094$} & \multicolumn{2}{|c|}{$-23,746.750$} & \multicolumn{2}{|c|}{$-23,600.458$} & \multicolumn{2}{|c|}{$-11,456.152$} \\
\hline
\end{tabular}

Note. Total number of individuals is 895 ; total number of person-years is 7,821 (4,366 for Voting).

voting in Tables 3 and 5 are based on presidential election years only (1968, 1972, 1976, and 1980). In all models, coefficients are on the logit scale. All of the $p$ values in the tables are for $H_{0}: \gamma=0$ versus $H_{A}: \gamma \neq 0$.

\section{ACKNOWLEDGMENTS}

An earlier version of this paper was presented at the second Minnesota Symposium on Political Psychology: Campaigns and Elections, 7-9 November 
2002. The current draft is much improved by comments from the symposium participants and from Gene Borgida, Henry Brady, Jamie Druckman, Kent Jennings, Joanne Miller, Eric Plutzer, Laura Stoker, John Sullivan, Cara Wong, and two anonymous reviewers. Thanks to Laura Stoker and Kent Jennings for providing access to the Political Socialization data set. Correspondence concerning this article should be sent to Jake Bowers, Department of Political Science, University of Michigan, Ann Arbor, MI 48106-1248. E-mail: jwbowers@umich.edu

\section{REFERENCES}

Bowers, J. (2003). The dynamics of political participation in the lives of ordinary Americans. Unpublished doctoral thesis, University of California, Berkeley.

Breslow, N. E., \& Clayton, D. G. (1993). Approximate inference in generalized linear mixed models. Journal of the American Statistical Association, 88, 9-25.

Diggle, P. J., Liang, K.-Y., \& Zeger, S. L. (1994). Analysis of longitudinal data. Oxford: Oxford University Press.

Fischer, C. (2002). Ever-more rooted Americans. City and Community, 1, 177-198.

Green, D. P., \& Cowden, J. A. (1992). Who protests: Self-interest and white opposition to busing. Journal of Politics, 54, 471-496.

Highton, B. (2000). Residential mobility, community mobility, and electoral participation. Political Behavior, 22, 109-120.

Huckfeldt, R. R. (1979). Political participation and the neighborhood social context. American Journal of Political Science, 23, 579-592.

Jennings, M. K., \& Markus, G. (1984). Partisan orientations over the long haul: Results from the threewave Political Socialization panel study. American Political Science Review, 78, 1000-1018.

Jennings, M. K., \& Niemi, R. G. (1981). Generations and politics: A panel study of young adults and their parents. Princeton, NJ: Princeton University Press.

Jennings, M. K., \& Stoker, L. (1997). The study of political socialization, 1965-1997 [Unpublished computer file containing data previously published and collected by M. K. Jennings et al. in 1965, 1973, and 1982].

Lane, R. E. (1959). Political life: Why people get involved in politics. Glencoe, NY: Free Press of Glencoe.

Lieberson, S., \& Waters, M. C. (1987). The location of ethnic and racial groups in the United States. Sociological Forum, 2, 780-810.

McCulloch, C. E., \& Searle, S. R. (2001). Generalized, linear, and mixed models. New York: Wiley.

Nie, N., Junn, J., \& Stehlik-Barry, K. (1996). Education and democratic citizenship in America. Chicago: University of Chicago Press.

Plutzer, E. (2002). Becoming a habitual voter: Inertia, resources and growth in young adulthood. American Political Science Review, 96, 41-56.

Putnam, R. D. (2000). Bowling alone: The collapse and revival of American community. New York: Simon and Schuster.

Raudenbush, S. W., \& Bryk, A. S. (2002). Hierarchical linear models: Applications and data analysis methods (2nd ed.). Thousand Oaks, CA: Sage.

Rosenstone, S., \& Hansen, J. M. (1993). Mobilization, participation and democracy in America. New York: Macmillan. 
Snijders, T., \& Bosker, R. (1999). Multilevel modeling: An introduction to basic and advanced multilevel modeling. London: Sage.

Squire, P., Wolfinger, R. E., \& Glass, D. P. (1987). Residential mobility and voter turnout. American Political Science Review, 81, 45-66.

Verba, S., \& Nie, N. H. (1972). Participation in America: Political democracy and social equality. New York: Harper and Row.

Verba, S., Schlozman, K. L., \& Brady, H. (1995). Voice and equality: Civic voluntarism in American politics. Cambridge, MA: Harvard University Press.

Wolfinger, R. E., \& Rosenstone, S. J. (1980). Who votes? New Haven, CT: Yale University Press. 